ultrasonography ${ }^{1}$ and abdominal computed tomography) showed no changes in the subcapsular hematoma with no active sources of bleeding (Figure 1). After a few days of observation in the hospital, the patient was discharged and followed up as an outpatient, with repeated follow-up abdominal ultrasonography showing normal resolution of the hematoma.

\section{DISCUSSION}

Splenic rupture after videothoracoscopic lung procedures is a very rare event. In the only case previously described in the literature, ${ }^{2}$ an emergency splenectomy was required after a splenic injury occurred during video-assisted pulmonary resection of a nonmalignant tumor. The suggested cause of injury was a transdiaphragmatic blunt trauma with intact diaphragm.

In our case we did not detect any direct evidence of a laceration of the diaphragm at the end of the videothoracoscopic procedure, and the ensuing radiographic examinations also yielded negative results. Transdiaphragmatic blunt trauma to the spleen was clearly caused by the positioning of one of the thoracoscopic ports (the lowest was inserted in the ninth intercostal space posteriorly) or by the insertion of the mechanical suture device (we have used the lowest one for the stapler), which can be troublesome if the pulmonary lesions are in close proximity to the chest wall.
Our trauma center experience suggests that conservative treatment was the ideal choice, particularly in managing a blunt trauma to parenchymal ${ }^{3}$ organs, for which angiographic arterial embolization is the preferred solution. ${ }^{4,5}$

In conclusion, splenic injuries occurring during thoracic surgery procedures may be safely managed conservatively in the presence of hemodynamic stability. Transdiaphragmatic insults to the spleen are likely to be single and localized and thus easy to control with an endovascular arterial embolization. Splenectomy should be the last viable option when conservative treatment fails or in case of sudden hemodynamic instability.

\section{References}

1. Cagini L, Gravante S, Malaspina CM, Cesarano E, Giganti M, Rebonato A, et al Contrast enhanced ultrasound (CEUS) in blunt abdominal trauma. Crit Ultrasound J. 2013;5(Suppl 1):S9.

2. Flores RM, Thekweazu U, Dycoco J, Rizk NP, Rusch VW, Bains MS, et al Video-assisted thoracoscopic surgery (VATS) lobectomy: catastrophic intraoperative complications. J Thorac Cardiovasc Surg. 2011;142:1412-7.

3. Peitzman AB, Heil B, Rivera L, Federle MB, Harbrecht BG, Clancy KD, et al. Blunt splenic injury in adults: Multi-Institutional Study of the Eastern Association for the Surgery of Trauma. J Trauma. 2000;49:177-87.

4. Di Saverio S, Giorgini E, Biscardi A, Sibilio A, Villani S, Naidoo N, et al. Surgical treatment of spleen trauma. In: Di Saverio S, Tugnoli G, Catena F, Ansaloni L, Naidoo N, eds. Trauma surgery: volume 2: thoracic and abdominal trauma. Milan: Springer Italia; 2014:117-34.

5. Bhullar IS, Frykberg ER, Siragusa D, Chesire D, Paul J, Tepas JJ III, et al Selective angiographic embolization of blunt splenic traumatic injuries in adults decreases failure rate of nonoperative management. J Trauma Acute Care Surg. 2012;72:1127-34.

\title{
Pyomyositis of the chest wall presenting with empyema thoracis
}

\author{
Olusola Oduntan, MD, FACS, ${ }^{a}$ and Arif R. Sarwari, MD, MSc, MBA, ${ }^{\mathrm{b}}$ Morgantown, WVa
}

Pyomyositis is an inflammatory condition of the skeletal muscle. It was first described by Scriba in 1885 as a disease endemic to the tropics, hence the term tropical pyomyositis. Until recently, pyomyositis was considered unusual in the temperate zone. ${ }^{1,2}$ Although any skeletal muscle may be involved, pyomyositis has

\footnotetext{
From the Division of Thoracic Surgery, ${ }^{\mathrm{a}}$ Department of Surgery, and the Section of Infectious Disease, ${ }^{b}$ Department of Medicine, West Virginia University, Morgantown, WVa.

Disclosures: Authors have nothing to disclose with regard to commercial support. Received for publication March 6, 2014; revisions received June 13, 2014; accepted for publication July 12, 2014; available ahead of print Aug 26, 2014.

Address for reprints: Olusola Oduntan, MD, FACS, PO Box 957, Morgantown, WV 26507 (E-mail: solaodunt@aol.com).

J Thorac Cardiovasc Surg 2014;148:e237-9

$0022-5223 / \$ 36.00$

Copyright (C) 2014 by The American Association for Thoracic Surgery

http://dx.doi.org/10.1016/j.jtcvs.2014.07.092
}

predilection for large muscle masses of the body. Multiple muscle involvement occurs in $12 \%$ to $60 \%$ of patients.

There are 3 stages of presentation. The first stage is the "invasive stage," with minimal signs of inflammation. There may be muscle pain, fever, and mild leukocytosis. The second stage is the "suppurative stage," between 10 and 20 days from the onset of symptoms. Signs of inflammation are more pronounced, with swelling, tenderness, and fever. Needle aspiration yields purulent exudate. The final stage is the "septicemic stage," when the patient is acutely ill, with high fever and toxicity. Occasionally, septicemia and coma may be seen.

Computed tomographic (CT) scan and magnetic resonance imaging are the best imaging techniques for early diagnosis and follow-up of the patient. 

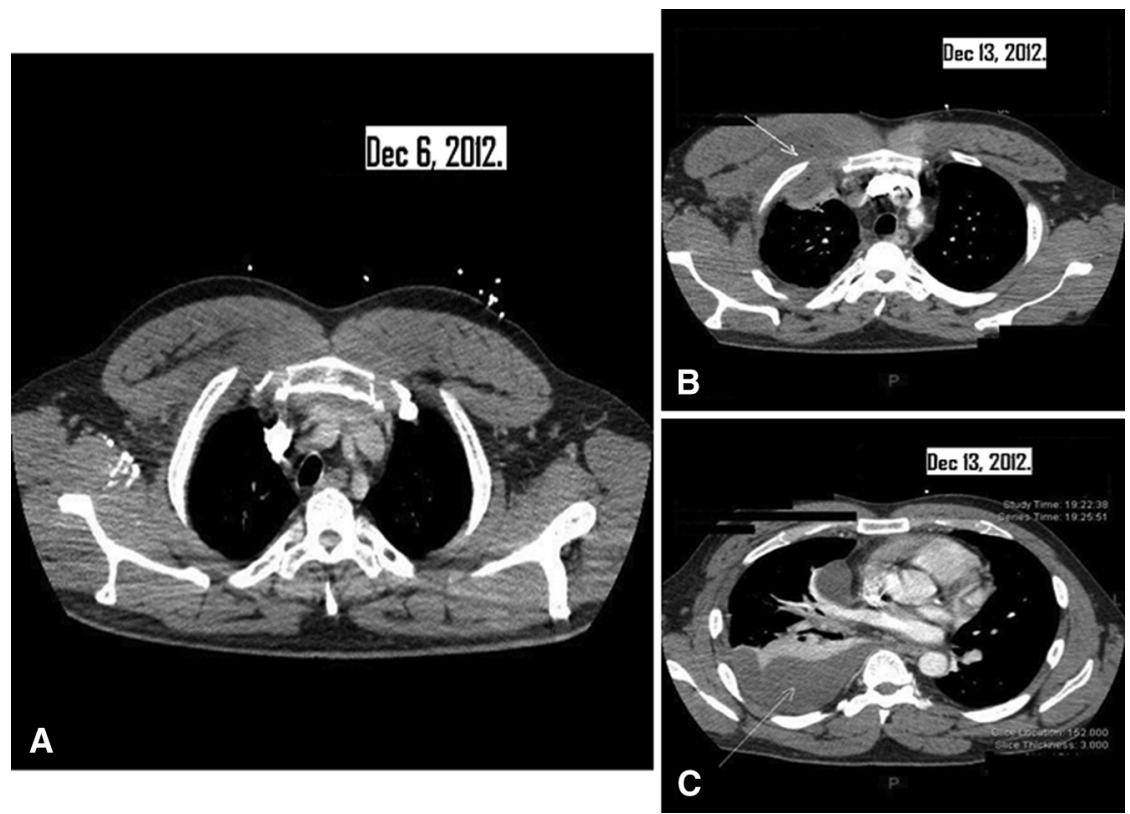

FIGURE 1. A, Computed tomographic scan of chest with no significant soft tissue or lung abnormalities reported. B, Right chest wall abscess in continuity with empyema thoracis (white arrow). C, Right pleural effusion (white arrow).

\section{CLINICAL SUMMARY}

A 46-year-old man came to an acute care hospital reporting pain and swelling over the right pectoralis muscle. Findings of a CT scan of the chest were reported as "normal" (Figure 1,A), and the patient was discharged home. A week later, he returned with worsening of symptoms. Repeated CT scan revealed swelling of the right chest wall, with $2.3 \times 7.1-\mathrm{cm}$ fluid collection deep to the pectoralis muscles, contiguous with a $5.3 \times 3.3-\mathrm{cm}$ loculated pleural fluid in the upper right hemithorax (Figure 1, B), with a large pleural effusion in the dependent portion of the chest (Figure 1,C). At this point, the patient was transferred to our thoracic surgery service.
On admission, the patient had a toxemic appearance, was mildly febrile, and had tachycardia. There was bulging of his right chest wall, measuring $11 \times 13 \mathrm{~cm}$, with tenderness of the right pectoralis muscle. His white blood cell count was 18,300 cells $/ \mu \mathrm{L}$.

The patient was started on a regimen of intravenous vancomycin and piperacillin with tazobactam and was taken to the operating room for video-assisted thoracoscopy. After evacuation of $800 \mathrm{~mL}$ of pus from the right pleural space, saline solution irrigation was performed, with decortication of the right lung, and large-bore chest tubes were placed. Incision and drainage of the pectoralis abscess was performed through an incision over the fluctuant portion on
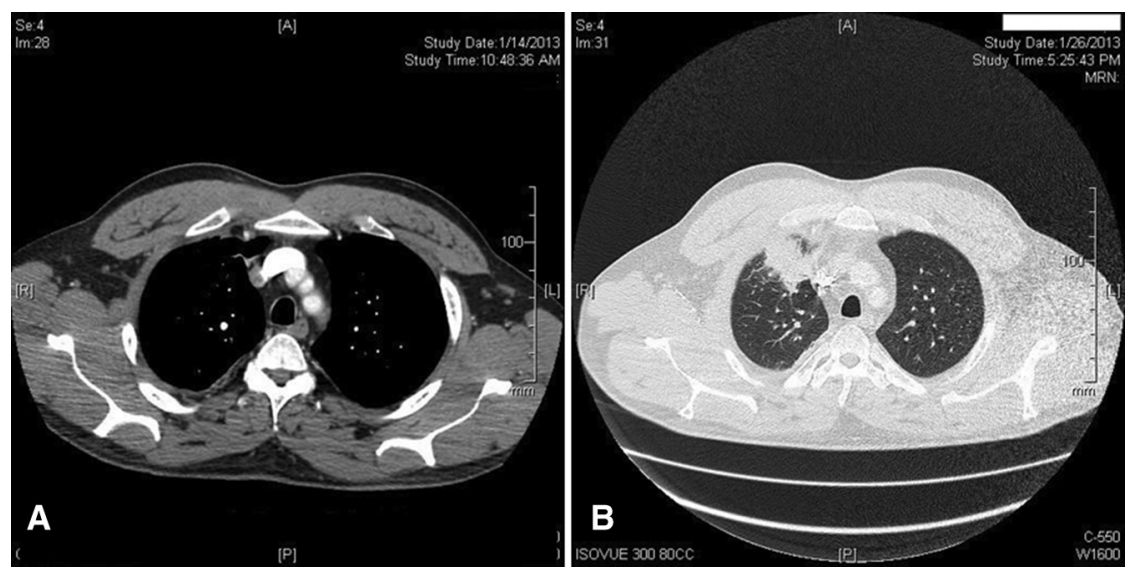

FIGURE 2. A, Chest computed tomographic scan showing complete resolution of chest wall swelling and empyema. B, Chest computed tomographic scan showing right upper lobe consolidation. 
the chest wall. The cavity was irrigated with saline solution, and a Jackson-Pratt drain was placed. Cultures of the empyema fluid and the pectoralis abscess revealed oxacillinsensitive Staphylococcus aureus. The antibiotic regimen was switched to clindamycin. The patient's white blood cell count returned to normal thereafter. The chest tubes and Jackson-Pratt drain were removed on postoperative days 8 and 10 , respectively. The patient was discharged on a regimen of oral clindamycin for 2 weeks.

The patient was seen in clinic 3 weeks after discharge. He had no symptoms, and physical examination yielded normal findings. Chest CT scan (Figure 2, A) also appeared normal.

The patient was seen 2 weeks later (5 weeks after discharge) with reports of pleuritic right chest pain without swelling. Repeated CT scan showed right upper lobe consolidation but no soft tissue collection (Figure 2, B). Infectious disease consultation was requested, and the patient was treated with intravenous nafcillin sodium (INN nafcillin) for 4 weeks as an inpatient. He did not require surgical reintervention.

\section{DISCUSSION}

We report the case of a patient with pyomyositis of the chest wall who was seen initially during the invasive stage and subsequently in the suppurative stage when the pyomyositis had become associated with empyema. We believe that the chest wall abscess burrowed through the deep pectoralis muscle to transgress the intercostal muscles and endothoracic fascial layers and finally drain into the pleural cavity. Review of imaging studies by expert radiologists eliminated bone and joint infection as a primary problem in this case. There was no evidence of lung or pleural disease on the initial CT scan, so we do not think that this was a case of lung abscess presenting with empyema necessitans. In addition, pectoralis muscle swelling could be noted on the initial scan, the findings of which had previously been reported as normal.

This case demonstrates the diagnosis of so called temperate pyomyositis in an otherwise immunecompetent individual. Case series of pyomyositis in the setting of injection drug use or human immunodeficiency virus infection have been documented previously. ${ }^{3,4} S$ aureus is the etiologic agent in $90 \%$ of cases. The most common predisposing factor in temperate regions is injection drug use, which the patient denied.

Prompt and adequate surgical drainage of abscesses was offered, but the disease recurred with pulmonary consolidation, attributable to the primary infection with $S$ aureus. This relapse could have been prevented had the antibiotic therapy been administered by the intravenous route for longer.

The association of pyomyositis with pyogenic pericarditis and empyema thoracis has been described in the tropical countries, notably in children with malnutrition and tuberculosis. ${ }^{5}$ A MEDLINE search did not bring up prior report of similar associations in the temperate world.

\section{References}

1. Small LN, Ross JJ. Tropical and temperate pyomyositis. Infect Dis Clin North Am 2005; 19:981-9.

2. Drosos G. Pyomyositis. A literature review. Acta Orthop Belg. 2005;71:9-16.

3. Ebright JR, Pieper B. Skin and soft tissue infections in injection drug users. Infect Dis Clin North Am. 2002;16:697-712.

4. Popescu GA. Immunocompromised host (especially HIV-positive) the target of pyomyositis in temperate regions. South Med J. 2008;101:235.

5. Adebonojo SA, Adebo OA, Osinowo O. Pattern of thoracic surgical diseases in Nigeria: experience at the University College Hospital, Ibadan. J Natl Med Assoc. 1978;70:651-7. 